\title{
Direito fundamental à liberdade de pesquisa genética e à proteção de dados pessoais: os princípios da prevenção e da precaução como garantia do direito à vida privada
}

\author{
FUNDAMENTAL RIGHT TO FREEDOM OF GENETIC'S \\ RESEARCH AND TO PERSONAL DATA PROTECTION: \\ THE PRINCIPLES OF PREVENTION AND PRECAUTION \\ AS GUARANTEE OF THE RIGHT TO PRIVATE LIFE
}

* Regina Linden Ruaro

RESUMO: O artigo analisa os direitos fundamentais de liberdade de pesquisa e da proteção de dados pessoais no campo da genética humana, propõe a aplicação dos princípios da precaução de da prevenção. Avalia a legislação brasileira na matéria objeto da pesquisa como medida de garantia à privacidade dos dados pessoais e das informações colhidas na investigação científica, situação que se agrava no meio no mundo digital e virtual por ser este um espaço praticamente de rápido desenvolvimento. Enfoca a limitação de direitos fundamentais, partindo da concepção de que não são absolutos. Propõe a aplicação dos princípios da precaução e da prevenção no meio ambiente virtual. Adotou-se os métodos dedutivo e dialético, tendo-se como premissa maior os direitos fundamentais relacionados e previstos na legislação brasileira; o método dialético foi empregado porque a questão é objeto de constante debate sendo necessário o confronto de correntes doutrinárias e a normativa brasileira.

PALAVRAS CHAVE: Liberdade de Pesquisa. Dados Genéticos. Precaução. Prevenção.

ABSTRACT: The article analyzes the fundamental rights to privacy and to freedom of research in the human genetics field, propose the application of the precaution's and prevention's principles. Evaluate the current situation of the brazilian legislation in order to guarantee the confidentiality of the personal data and of the collected information in the scientific research, situation that worsens in the digital and virtual environment, due to its being practically a space of fast development. Focus on the limitation of fundamental rights, once they are not absolute. Proposes the application of the principles of precaution and prevention in the virtual 
environment. Adopts the deductive and dialect methods, using as bigger premise the fundamental rights related and prescribed on the brazilian legislation; the dialectic method was adopted because the question is object of constant debate being necessary the confrontation between doctrinaire currents and the brazilian law.

KEYWORDS: Freedom of Research. Genetic's data. Precaution. Prevention 


\section{INTRODUÇÃO}

O uso das novas tecnologias leva a refletir sobre a importância que adquiriu manter a vida privada longe dos olhos do "grande irmão"1. Tal ideia deriva da fragilidade tem se fragilizado. Na atualidade transita-se em mundos virtuais, também chamados de “mundos digitais” e nesta esfera há muitos tipos diferentes de “mundos virtuais””. Esses mundos têm características comuns. A primeira delas, é que se constituem em um espaço compartilhado, ou seja, vários usuários podem participar de forma instantanea; a segunda, se refere à chamada "interface gráfica do usuário”, pela qual se pode retratar o espaço visualmente a partir de vários estilos de imersão; a terceira, é a imediatividade, as interações ocorrem em tempo real; como quarta característica, apresenta-se a interatividade, que permite aos usuários alterar, desenvolver, construir ou tornar o conteúdo personalizado; a quinta, chamamos de persistência, porque no "mundo virtual” mesmo que o indivíduo não esteja conectado, suas informações seguem existindo; como sexta característica, apresenta-se a socialização/ participativa como estimulante do agrupamento de grupos sociais e reivindicações comuns; por fim, agregamos mais uma característica, a perenidade, as informações não se encontram somente no IP do cumputador em que as registramos mas em espaços ao qual o mundo da computação chama de "nuvem” lá permanecendo indefinidamente.

Para além de espaços abrangentes e abertos à comunidade em geral, tem-se também os chamados "espaços restritos" que se criam a partir de áreas de interesses comuns e do qual somente fazem parte um grupo determinado de pessoas. Neste "mundo virtual", ao qual também podemos chamar de "meio ambiente virtual”, é que se inserem dados pessoais coletados e transferidos pelos pesquisadores científicos nos diversos pontos da “arena global”.

No campo da pesquisa genética em seres humanos, o direito defrontase com o desafio de garantir que a liberdade de pesquisa seja preservada. Mas tem de preocupar-se, ainda, com outros direitos não menos importantes: da privacidade, da proteção de dados pessoais dos sujeitos pesquisados, do livre desenvolvimento da personalidade; do princípio da igualdade de oportunidades; da dignidade e da integridade das pessoas (RUARO; LIMBERGER, 2013).

${ }^{1}$ Expressão utilizada por George Orwell em sua célebre obra "1984”. 
Notadamente em nosso país, a segurança dos bancos de dados e da internet ainda carece de maior atenção, muito embora já se tenha um marco legal ${ }^{2}$ relativamente à matéria que expressamente prevê como princípio, a privacidade. A lei delega a proteção de dados pessoais a uma norma específica que, até o momento, se constitui apenas em um Projeto ${ }^{3}$ em tramitação no Congresso Nacional.

O meio ambiente virtual apresenta facetas muito distintas do meio ambiente compreendido normalmente porque sua dimensão não pode ser limitada nem pelo espaço e tampouco pelo tempo. O espaço, como dissemos, está nas "nuvens" que se constituem em grande centros de computadores armazenadores dos arquivos de qualquer pessoa sem o prévio consentimento informado.

Não se pode pretender retomar discurso Ludditie ${ }^{4}$ até porque são inegáveis os benefícieos que as tecologias da informação e da comunicação aportam e têm ainda a aportar ao mundo das ciências, à economia e às relações pessoais em geral. Trata-se apenas de propor que neste meio ambiente virtual ao qual se está inserido, sejam adotados princípios jurídicos capazes de evitar males muitas vezes irreversíveis para os cidadãos pesquisados. Outro fator não menos importante para a Ciência Jurídica é garantir a coexistência de vários dos direitos fundamentais compatibilizando-os, pois estes resultam de um processo histórico caramente conquistado pela humanidade.

O presente artigo é resultado parcial de uma pesquisa científica ${ }^{5}$ que trabalha com o tratamento de informações genéticas em confronto com outros direitos fundamentais em seu entorno, bem como suas implicações, na perspectiva de um marco regulatório de proteção de dados pessoais que tratem diretamente da questão.

A partir do material coletado e da revisão literária realizada até o presente estágio da investigação, já se pode concluir que, no meio ambiente virtual, em específico àquele onde se armazenam e transferem dados da pesquisa científica voltada para a genética dos seres humanos, torna-se imprescindível a aplicação dos princípios da precaução e da prevenção, típicos do Direito Ambiental e basilares na preservação da dignidade da pessoa humana. Aventa-se que tais princípios sejam capazes de garantir a convivência

\footnotetext{
Lei $12.965 / 2014$.

3 PL 4060/2012.

${ }^{4}$ Movimento de operários ingleses que no século XIX destruíram máquinas em plena Revolução Industrial com medo de perder seus empregos que reaparece hoje pelo temor às novas Tecnologias da Informação e Comunicação.

5 EDITAL UNIVERSAL/CNPq 14/2013.
} 
dos direitos fundamentais de liberdade de pesquisa, intimidade e vida privada dos sujeitos pesquisados.

Neste estado da questão se impõe discutir procurando respostas acerca de problemas como: (a) de que forma se pode compatibilizar direitos consagrados na Constituição Federal de 1988 diretamente relacionados com a dignidade da pessoa humana - como o respeito à vida privada e à intimidade - frente à liberdade de pesquisa genética? (b) qual o significado que uma tutela aos dados pessoais no campo da informação genética recebe do ordenamento jurídico brasileiro? (c) a aplicação dos princípios da prevenção e da precaução no meio ambiente virtual é imprescindível para a consecução dos direitos fundamentais objeto do estudo?

Para responder às questões propostas foram adotados os métodos dedutivo e dialético, pois se teve como premissa maior os direitos fundamentais relacionados ao tema do estudo previstos na Constituição Federal Brasileira. O método dialético foi empregado porque o tema em questão merece constante debate tornando-se necessário o confronto de opiniões e correntes doutrinárias e a normativa brasileira.

\section{A LIBERDADE DE PESQUISA GENÉTICA EM CONTRAPO- SIÇÃO À PRIVACIDADE EM UMA PERSPECTIVA DE PRO- TEÇÃO DE DADOS PESSOAIS}

As novas tecnologias induzem a uma, também nova, conformação do tempo e do espaço, o virtual substitui o físico gerando realidades que por vezes conduzem ao desrespeito de direitos fundamentais e de outros direitos que daí decorrem.

Não resta dúvida de que o momento proíbe e impossibilita um retrocesso no avanço nas tecnologias de armazenamento, de tratamento, de difusão da informação e do conhecimento, até porque não há um controle possível sobre esta realidade. No entanto, abre-se, para os operadores do Direito a necessidade de uma reflexão que discuta e adote formas para minimizar e evitar riscos, sobretudo no que se refere aos dados pessoais sensíveis das pessoas ${ }^{6}$ sujeitos de pesquisa genética, que devem ser tutelados.

\footnotetext{
${ }^{6}$ Os dados genéticos são definidos como dados pessoais porque se referem a uma pessoa identificada ou identificável. Os dados pessoais sensíveis referem-se a aspectos mais íntimos do indivíduo como a religião, vida sexual, saúde, ideologia política, dados genéticos e outros que daí decorram.
} 
No cenário da pesquisa em genética humana, o corpo-informação emerge, fundamentalmente, do cruzamento da cibernética, da biologia molecular e das tecnologias da informação que acabam por dar suporte ao mais recente paradigma tecnológico: o molecular-digital. A partir de então, o corpo humano deixa de ter uma arquitetura predominantemente orgânica e mecânica para constituir-se como um "sistema de informação" ou, "sistema de dados pessoais genéticos”.

Mais do que obedecer a leis da física e da mecânica, o corpo humano está sujeito aos princípios da cibernética e da informática (a lógica de programação, a linguagem numérica do computador). O que define o organismo vivo é o envio e a recepção de mensagens, é o código genético inscrito no DNA (CÖRREA, 2009).

Carlos Maria Romeo Casabona (2002, p. 26) aponta fatores das descobertas do genoma humano e seus efeitos. Destaca em seu livro que:

As descobertas sobre o genoma humano acentuaram uma forte tendência que, já faz anos, vem sendo observada nas ciências biomédicas em geral: a multidisciplinaridade. Sua necessidade metodológica vem sendo imposta de forma natural como consequência(sic) da enorme complexidade que envolve uma análise mais profunda sobre os efeitos importantes e diversificados que elas podem produzir para o ser humano.

Com tais preocupações, vários instrumentos internacionais estabelecem princípios necessários a serem empregados na pesquisa genética. Pode-se citar quatro Declarações Internacionais: Declaração Universal sobre o Genoma Humano e os Direitos Humanos, a Direitos Declaração Internacional sobre Dados Genéticos Humanos, a Declaração Universal de Bioética e Direitos Humanos e a Declaração das Nações Humanas sobre a Clonagem Humana.

Importante salientar que, na análise dos textos das Declarações Internacionais se percebe como nota comum a todas elas a afirmação de princípios básicos: da dignidade humana e da liberdade de pesquisa científica.

As Declarações Internacionais não trabalham com os princípios que devem ser levados em conta no que se refere ao tratamento, utilização e conservação de dados genéticos, porém, remetem aos Estados a competência para as medidas legais e administrativas necessárias ao adequado respeito aos princípios que proclamam (PETERLE, 2007).

No campo da privacidade, segurança da pessoa, e conservação de dados genéticos, a matéria foi abordada na Declaração Internacional sobre Dados 
Genéticos Humanos ${ }^{7}$ referindo o meio ambiente como fator a ser levado em consideração na identificação genética da pessoa. ${ }^{8}$

As referidas diretrizes, em vista dos princípios que proclamam, demonstram a importância dos riscos eventuais que a pesquisa genética humana apresenta indicando claramente a preocupação de os seres humanos perderem a sua condição de sujeito de direito para se tornarem um simples objeto de manipulação (SANTOS, 2001).

Essa realidade se evidencia no fato de que a pesquisa genética humana trabalha com genoma humano e este, por sua vez, comporta uma faceta da dignidade dos indivíduos o que implica na necessidade de uma proteção máxima. Uma proteção que lhes faculte decidir sobre quando e como se poderá reunir suas informações genéticas, a sua finalidade e armazenamento, bem como, a transferência. Bem colocadas as palavras de Joaquim Clotet (2003, p. 119):

O genoma humano constitui um valor em si próprio que comporta a dignidade do ser humano como indivíduo singular e a dignidade da espécie humana como um todo. O genoma humano, considerado de forma ora individual ora coletiva deve ser respeitado e protegido. Cabe à pessoa, em virtude de sua autonomia como sujeito, decidir sobre a informação do próprio genoma, bem como sobre as intervenções terapêuticas e aperfeiçoadoras no mesmo, no que se refere às células somáticas. A intervenção nas células germinativas das pessoas, já que os seus efeitos serão transmitidos a seus descendentes, ultrapassa os limites da autonomia pessoal, pois trata-se do genoma humano como patrimônio da humanidade.

Em vista disso, entende-se que é possível e necessário que os Estados levem em consideração que os dados muitas vezes são tratados, armazenados e transferidos no "meio ambiente virtual” o que implicaria na adoção dos princípios da precaução e prevenção como garantidores de todos os demais princípios constitucionais.

Diante de tal realidade como se pode estabelecer o espaço possível de uma coexistência jurídico-legal de direitos fundamentais capazes de entrarem

\footnotetext{
7 Para um aprofundamento na análise dos textos Internacionais, vide Peterle (2007).

8 A Declaração Internacional de Dados Genéticos Humanos da UNESCO (art. $2^{\circ}$ ) define rês espécies de dados. (i) dados associados a uma pessoa identificável, como os que contêm informações como o nome, a data de nascimento e o endereço; (ii)dados dissociados de uma pessoa identificável, como dados associados a uma pessoa não identificável, os dados foram desconectados da pessoa identificável; (iii) dados irreversivelmente dissociados de uma pessoa identificável, como os que tiveram destruído o nexo com a informação impossibilitando sua conexão com a pessoa identificável.
} 
em rota de colisão em algum momento? Como então viabilizar a liberdade da pesquisa genética com a proteção dos dados sensíveis dos indivíduos?

\section{LIMITES E RESTRIÇÕES AOS DIREITOS FUNDAMENTAIS EM COLISÃO}

A importância da pesquisa genética tem levado ao avanço da medicina, à cura de doenças que até então acometiam de forma irreversível os seres humanos. Neste sentido, Gisele Echtterhoff (2010, p. 42) aponta em seus estudos que é "impossível se apontarem todos os benefícios advindos do desenvolvimento do conhecimento científico no âmbito da Genética e da Engenharia Genética”. Porém, em sua obra manifesta, também, uma preocupação com a possibilidade de que todos os conhecimentos gerados nesta matéria possam acarretar problemas e "dilemas éticos, morais, sociais e jurídicos que estão assombrando a humanidade” (ECHTTERHOFF, 2010, p. 52). Efetivamente, é pacífico que com todos os avanços surgiram os problemas.

Otto y Pardo (1988, p. 110) quando trata dos limites imanentes dos direitos fundamentais defende a necessária existência de uma conciliação de um com os demais. O autor sustenta textualmente:

Los derechos fundamentales no están sometidos únicamente a lós limites que de manera expresa lês imponen las normas constitucionales que lós reconocen, sino también a lós que resulten justificadas por La protección de lós derechos y bienes a que se alude, esto es, están sujetos a uma limitación genérica establecida de modo tácito para todo derecho.

Por seu lado, Ingo Sarlet (2015, p. 405-406) ao estudar o a proteção dos direitos fundamentais salienta que

[...] a ideia de que os direitos fundamentais não são absolutos, no sentido de absolutamente blindados contra qualquer tipo de restrição na sua esfera subjetiva e objetiva, não tem oferecido maiores dificuldades, tendo sido, de resto, amplamente aceito no direito constitucional contemporâneo.

Efetivamente, não se pode pretender e, sequer seria factível, que todos os direitos fundamentais tivessem um caráter absoluto e isto porque com tal premissa, dentre outros fatores, para o objeto do estudo aqui realizado, em eventual colisão entre um e outro, se estaria diante de um problema jurídico 
sem solução. Assim, éimperativo ao sistema jurídico apresentar soluções que sejam capazes de resolver colisões de direitos.

Seguindo em sua linha de raciocínio, Ingo Sarlet (2015), entende que para discutir-se a matéria há de se contrapor as teorias interna e externa dos limites aos direitos fundamentais. Saliente-se que a posição desse autor, por nós compartilhada, é a da aplicação da “teoria mista” ao qual será tratada mais adiante.

De acordo com a "teoria interna” os direitos fundamentais "nascem” limitados, ou seja, têm "limites imanentes” e tem apenas um objeto - direito e seus limites - (SILVA, 2014), são uma só coisa, o que significa dizer que o direito em sua origem já tem implicitamente uma restrição.

Virgílio da Silva (2014, p. 130) acerca da teoria interna aponta que:

[...] no âmbito da teoria interna não há como falar que determinada ação seja prima facie garantida por uma norma de direito fundamental mas que, em decorrência de circunstâncias - fáticas e jurídicas - do caso concreto, tal ação deixe de ser protegida.

A crítica de Ingo Sarlet a esta teoria reside no fato de que em face dos seus postulados, a mesma pode ser fragilizada afirmando textualmente:

[...] a ausência, por parte da teoria interna, de separação entre o âmbito de proteção e os limites dos direitos fundamentais permite que sejam incluídas considerações relativas a outros bens dignos de proteção (por exemplo, interesses coletivos ou estatais) no próprio âmbito de proteção dos direitos, o que aumenta o risco de restrições arbitrárias da liberdade. (SARLET; MARINONI; MITIDIERO, 2014, p. 342).

Concorda-se com o autor em que tomar-se como postulado a "teoria interna” na resolução dos limites da liberdade de pesquisa na área da genética quando confrontada com o direito à intimidade e da necessidade de proteção de dados pessoais se correria o sério risco de dar azo à restrição dos avanços científicos, sobretudo da medicina diante de ideias mais conservadoras advindas de interesses coletivos ou mesmo do Estado que é o maior fomentador com recursos financeiros e de infraestrutura na área da investigação científica.

Seguindo-se com a análise das teorias de limitações de direitos fundamentais, na matéria, Virgílio Afonso da Silva (2014, p. 138), tece considerações acerca da teoria externa diferenciando-a da teoria interna na 
medida em que a teoria externa tem seu objeto dividido em dois momentos. "Em primeiro lugar está o direito em si e, em face de situações concretas posteriores sofreria suas restrições". ${ }^{9}$

Trasladando-se a teoria externa ao objeto deste estudo ter-se-ia que o direito à liberdade de pesquisa na área de genética humana é um direito fundamental pleno que leva consigo todas as prerrogativas dos direitos fundamentais em sua origem. No entanto, se vem a sofrer alguma restrição por fatores externos passará a ser limitado. Consequentemente, a limitação do direito somente se evidenciaria quando houvesse colisão com o direito à intimidade e à proteção de dados pessoais, momento ao qual se toma o direito prima facie com todo o seu conteúdo para após, entendê-lo em sua posição definitiva já limitada.

Conforme dito anteriormente, Ingo Sarlet propõe uma teoria mista. Para o estudioso, o problema da limitação de um direito fundamental se evidencia quando o conflito se dá entre direitos não regulamentados. Neste sentido, alerta: "há casos em que a ausência de regulação esbarra na necessidade de resolver o conflito decorrente da simultânea tutela constitucional de valores ou bens que se apresentam em contradição concreta.” (SARLET, 2015a, p. 412)

Para exemplificar seu entendimento, o autor cita exatamente o exemplo da colisão dos direitos objeto do estudo ora realizado afirmando em palavras textuais:

Hipótese clássica diz respeito à liberdade de expressão, prevista no art. $5^{\circ}$, IX, da CF ("é livre a expressão da atividade intelectual, artística, científica e de comunicação, independentemente de censura ou licença”), que, a despeito de não sujeita à reserva legal, podem entrar em rota de colisão com outros direitos fundamentais, como por exemplo, os direitos à intimidade, à intimidade (sic) ${ }^{10}$ à honra e à imagem (art. $5^{\circ}, \mathrm{X}, \mathrm{CF}$ ), igualmente não sujeita à reserva de lei." (SARLET, 2015a, p. 412)

A melhor solução, segundo o estudioso, é aquela que respeita uma “ordem hierárquica abstrata dos valores constitucionais” (SARLET, 2015a, p. 412) onde não se sacrifique nem os valores nem os bens protegidos de forma racional.

9 SILVA, Virgílio Afonso da. Direitos fundamentais. Conteúdo essencial, restrições e eficácia. $2^{\mathrm{a}}$ ed., $3^{\mathrm{a}}$ tiragem. São Paulo: Malheiros Editores. 2014. p.138.

${ }^{10}$ Por equivoco constou duas vezes a expressão intimidade quando se pode induzir que o autor estaria invocando "privacidade" 


\section{A PROTEÇÃO DO DIREITO À PRIVACIDADE DOS DADOS PESSOAIS GENÉTICOS EM FACE DA DIGNIDADE DA PESSOA HUMANA}

Tratar do direito à privacidade remete ao artigo publicado por Samuel D. Warren e Luis D. Brandeis, em dezembro de 1890, na Harvard Law Review, intitulado The Right to Privacy"11, no qual os autores defendem que "o direito à vida passou a significar o direito de aproveitar a vida, - o direito de ser deixado só” (WARREN; BRANDIES, 1980). O estudo é tido como marco do surgimento desse direito no âmbito teórico-jurídico.

Ao trabalharem a questão do right to be let alone (direito de ser deixado só) diante das constantes invasões da imprensa no âmbito da vida privada e da vida doméstica, os autores enfatizaram a necessidade de se proteger da constante ameaça ao direito à privacidade (WARREN; BRANDIES, 1980).

O grande avanço desse estudo foi o de ensejar a migração do direito à privacidade, que antes se encontrava no âmbito dos direitos reais, para o âmbito dos direitos pessoais. Percebe-se que tal condição é a mais condizente com o Estado Constitucional de vez que, tratar da privacidade como um direito pessoal estabelece sua intima relação com a dignidade da pessoa humana.

A partir da premissa maior: O direito à privacidade está diretamente relacionado à dignidade da pessoa (humana), é que se impõe encontrar o ponto de equilíbrio entre a liberdade de pesquisa genética humana e a privacidade e para garanti-la, associar-se os princípios da precaução e prevenção na manipulação dos dados pessoais. Tal perspectiva demandará justamente a aplicação dos critérios capazes de evidenciar os valores estão sendo avaliados na forma como propõe Ingo Sarlet (2015a).

Em nosso ordenamento jurídico, o direito à privacidade, é tutelado pelo artigo $5^{\circ}$, inciso X da Constituição Federal brasileira, estando inserido no rol dos direitos de personalidade. Enquanto a “esfera individual” é inerente a honra e diz respeito ao nome, à reputação e à imagem do titular, a esfera privada nos remete à individualidade e a não intromissão externa na intimidade do titular, garantindo um certo isolamento do ser humano frente a seus semelhantes (VIEIRA, 2007).

Consoante Danilo Doneda (2014):

\footnotetext{
${ }^{11}$ Já trabalhamos com este artigo em publicação anterior. Banco de dados de informações genéticas e a Administração Pública como concretizadora da proteção dos dados pessoais e da dignidade humana. O artigo foi publicado na Revista Novos Estudos Jurídicos, vol. 18, nº 1/2013.
} 
A privacidade é componente essencial da formação da pessoa. A sutil definição do que é exposto ou não sobre alguém, do que se quer tornar público ou o que se quer esconder, ou a quem se deseja revelar algo, mais do que meramente uma preferência ou capricho, define propriamente o que é um indivíduo - quais suas fronteiras com os demais, qual seu grau de interação e comunicação com seus conhecidos, seus familiares e todos os demais.

Em suma, pode-se trabalhar com uma esfera social-individual e outra privada. Os atos inerentes à primeira esfera (Individualsphäre), dizem respeito a comportamentos abertos - aqueles facilmente perceptíveis e valorados - do indivíduo (COSTA JÚNIOR, 1970). Em outras palavras, tal esfera confundese com o direito à honra propriamente dito, protegendo o titular contra difamações. Em contraposto, a esfera privada abarca os chamados comportamentos encobertos que o indivíduo pretende manter a par do conhecimento e da interferência alheia (HENKEL, 1958, apud COSTA JÚNIOR, 1970), ou seja, diz respeito ao direito à privacidade, é justamente neste tópico que se inserem os dados pessoais.

Corroborando o entendimento de que na esfera da privacidade encontram-se os dados pessoais está Tatiana Malta Vieira (2007, p. 30) aduzindo que:

O direito à privacidade consistiria em um direito subjetivo de toda pessoa brasileira ou estrangeira, residente ou transeunte, física ou jurídica - não apenas de constranger os outros a respeitaram sua esfera privada, mas também de controlar suas informações de caráter pessoal - sejam estas sensíveis ou não - resistindo às intromissões indevidas provenientes de terceiros.

Importa salientar que segundo a autora, a privacidade pode ser dividida em diferentes categorias: (a) privacidade física - proteção contra procedimentos invasivos não autorizados como exames genéticos ou testes de drogas; (b) privacidade do domicílio - é aquela prevista no artigo $5^{\circ}$, inciso XI da Constituição Federal que dispõe: “a casa é asilo inviolável do indivíduo, ninguém nela podendo penetrar sem consentimento do morador, salvo em caso de flagrante delito ou desastre, ou para prestar socorro, ou, durante o dia, por determinação judicial”; (c) privacidade das comunicações - também encontra respaldo constitucional (art. 5, XII); (d) privacidade decisional ou direito à autodeterminação - consiste no poder de decisão do indivíduo. E, por fim, (e) privacidade informacional ou autodeterminação informativa (VIEIRA, 2007). 
John L. Mills, abordou o tema desde outras perspectivas atribuindo aos espaços de privacidade a esfera da autonomia, a esfera das informações pessoais, a esfera da propriedade pessoal e a esfera do espaço físico.

A esfera da autonomia atrela a privacidade a questões de identidade e de liberdade pessoal abordando liberdade de expressão e religiosa dentre outras. A esfera das informações pessoais, diz respeito ao direito à autodeterminação informativa ou privacidade informacional. A esfera da propriedade pessoal vincula-se a questões como propriedade (privada), posse, disposição do bem e outros aspectos dos direitos das coisas. Por fim, a esfera do espaço físico visa o respeito ao espaço pessoal, prescindindo da noção de propriedade para que seja respeitado, nos EUA, tal esfera é tutelada pela Tort Law (MILLS, 2008 apud RUARO; RODRIGUEZ, 2011).

Ao tomar-se os direitos à liberdade científica (pesquisa), a intimidade e privacidade ver-se-á que são direitos que não sofrem limitações através de legislações ordinárias. ${ }^{12}$ É justamente este o ponto de dificuldade de harmonia do sistema jurídico para dar a resposta das eventuais colisões.

\section{DIGNIDADE DA PESSOA HUMANAARTICULADA COM OS DIREITOS FUNDAMENTAIS DE LIBERDADE DE PESQUISA GENÉTICA E DA PRIVACIDADE}

A dignidade da pessoa humana é princípio fundamental da Constituição Brasileira (CF/88, art. 1º , III), sendo inerente ao próprio Estado Democrático de Direito, integrando sua estrutura.

Ao dispor sobre os princípios fundamentais na parte inaugural da Constituição, o legislador Constituinte deixou de forma clara e inequívoca sua intenção de outorgar aos mesmos o caráter embasador e informativo de toda a ordem constitucional, integrando o que pode se chamar de núcleo essencial da Constituição material (SARLET, 2015a).

Ao estudar a questão J.J. Gomes Canotilho (2000, p. 1165) ensina que:

Consideram-se princípios jurídicos fundamentais os princípios historicamente objetivados e progressivamente introduzidos na consciência jurídica e que encontram recepção expressa ou implícita no texto constitucional. Pertencem à ordem jurídica positiva e constituem um

\footnotetext{
${ }^{12}$ A respeito do tema vide Ingo Sarlet em sua obra Eficácia dos Direitos Fundamentais no item 4.2.3 "Os limites dos direitos fundamentais”.
} 
importante fundamento para a interpretação, integração, conhecimento e aplicação do direito positivo.

É perceptível e inegável a correspondência entre o princípio da dignidade da pessoa humana, os direitos fundamentais com os direitos de liberdade, de intimidade, privacidade e proteção de dados pessoais, verificando-se assim uma vinculação entre os direitos e os princípios fundamentais (SARLET, 2015a).

Ingo Sarlet (2015b, p. 70) propõe uma conceituação jurídica para a dignidade da pessoa humana ensinando que:

[...] por dignidade da pessoa humana a qualidade intrínseca e distintiva reconhecida em cada ser humano que o faz merecedor do mesmo respeito e consideração por parte do Estado e da comunidade, implicando, neste sentido, um complexo de direitos e deveres fundamentais que assegurem a pessoa tanto contra todo e qualquer ato de cunho degradante e desumano, como venham a lhe garantir as condições existenciais mínimas para uma vida saudável, além de propiciar e promover sua participação ativa e corresponsável nos destinos da própria existência e da vida em comunhão com os demais seres que integram a rede da vida."

Stefano Rodotà (2008, p. 237-238) compreende que a função sociopolítica da privacidade se projeta como elemento constitutivo da cidadania, figurando a dignidade, ao seu turno, como síntese dos princípios que visam a não redução da pessoa a fins mercadológicos, harmonizando-se com o respeito à igualdade e, principalmente, afastando a possibilidade de interferências não desejadas na vida do individuo:

Projetada na sociedade, esta reconstrução das relações entre privacidade e dignidade se apresenta como fator fundamental para o contraste das potentes lógicas que impulsionam a transformação das nossas organizações sociais em sociedades de vigilância, da classificação, da seleção discriminatória. Uma tarefa, todavia, que parece se tornar cada vez mais difícil.

Alexandre de Moraes (2005, p. 128) conceitua a dignidade da pessoa humana da seguinte forma:

A dignidade da pessoa humana é um valor espiritual e moral inerente à pessoa, que se manifesta singularmente na autodeterminação consciente e responsável da própria vida e que traz consigo a pretensão ao respeito por parte das demais pessoas, constituindo-se em um mínimo invulnerável que 
todo estatuto jurídico deve assegurar, de modo que apenas excepcionalmente possam ser feitas limitações ao exercício dos direitos fundamentais, mas sempre sem menosprezar a necessária estima que merecem todas as pessoas enquanto seres humanos.

No que toca à positivação do princípio da dignidade humana esta é relativamente recente, ressalvando-se uma ou outra exceção, somente após a Segunda Guerra Mundial que o valor fundamental da dignidade humana passou a ser expressamente reconhecido nas Constituições, de modo especial após ter sido consagrado pela Declaração Universal da ONU de 1948.

A dignidade da pessoa humana é fonte primária que apresenta as diretrizes do ordenamento jurídico dos Estados de Direito, representando vetor interpretativo e indicativo, e em se tratando do direito brasileiro, apresenta-se como um dos fundamentos do próprio Estado Democrático de Direito.

A efetivação de políticas públicas de proteção de dados pessoais, em atenção às garantias fundamentais estabelecidas em um Estado Democrático de Direito, salientam ainda mais a estreita relação entre liberdade, privacidade e dignidade. Isso porque, sem dispor de uma robusta tutela das informações que digam respeito à pessoa - o que hoje, pode-se afirmar, constitui espécie de corpo eletrônico do ser humano ${ }^{13}$-, estará o Poder Público permitindo não só a intrusão de terceiros na sua esfera privada, mas também se omitindo na garantia de outros direitos fundamentais, como aqueles atinentes às condições de trabalho, acesso ao crédito e saúde.

Nessa perspectiva é que se insere a necessidade de uma lei que regule a proteção de dados pessoais garantindo a privacidade e a intimidade dos sujeitos que são pesquisados geneticamente. Uma legislação especifica que abarque o meio ambiente físico e virtual sem contudo, inviabilizar a própria pesquisa cientifica. Tal concepção se enrobustece, na medida em que a realidade mundial em matéria de segurança dos sistemas informacionais tem dado mostras de sua fragilidade.

Com isso, sobressai que, se a liberdade a liberdade de pesquisa não é um direito absoluto, por esta razão sua compreensão deve vir permeada pela ética entre pesquisador e sujeito pesquisado, pautada nos princípios da não divulgação, da boa-fé ou lealdade ${ }^{14}$, da autodeterminação informativa e do direito a esclarecimentos.

${ }^{13}$ Quanto a este conceito, Cf. RODOTÀ, 2008, p. 233.

${ }^{14} \mathrm{O}$ princípio da lealdade e da boa-fé traduz-se na necessidade de consentimento prévio do titular para a coleta de seus dados e que estes sejam utilizados apenas para os fins aos quais foram coletados. 


\section{O ORDENAMENTO JURÍDICO BRASILEIRO EM MATÉRIA DE DADOS PESSOAIS GENÉTICOS}

Na sociedade informatizada, são trocados dados pessoais, com elevada frequência. Estes dados representam valioso instrumento, além de informações essenciais, para empresas privadas e autoridades públicas, já que permitem o desenvolvimento de políticas públicas mais eficientes. No entanto, muitas vezes são tratados sem qualquer preocupação com a sua segurança tornando seu armazenamento, transferência e manipulação, elementos ameaçadores dos direitos individuais.

Para enfrentar essa realidade, Pietro de Jesús Lora Alarcón (2004, p. 172) elucida o fenômeno do constitucionalismo contemporâneo e suas origens com o choque constitucional da atualidade, proveniente da importação de modelos norte-americanos, esclarecendo da necessidade de o direito acompanhar a evolução da sociedade e não ficar estagnado frente aos avanços biotécnicossociais.

É sabido que o constitucionalismo contemporâneo tem suas origens nos processos revolucionários de Inglaterra, Estados Unidos e França. No Brasil, atualmente, assistimos a uma fase peculiar de desenvolvimento do constitucionalismo americano, onde as opções políticas, econômicas, culturais, no mais das vezes, parecem confrontar-se com as normas constantes no texto. Esse choque, que pode ocasionar fenômenos de mutação constitucional, requer do intérprete uma formulação de acordo com as novas realidades, que consiste em descobrir novos caminhos jurídicos para resolver problemas novos, ainda que sempre com fulcro nos direitos fundamentais do ser humano. Hoje, a exigência para o jurista continua a ser a de outorgar conteúdo a cada norma, observando-a meticulosamente, em função de um raciocínio científico-jurídico que prestigie a evolução dessa categoria de direitos.

No Brasil, pode-se encontrar regras na Carta Magna, a partir das quais seria possível, através da analogia, a aplicação em casos concretos. Algumas das normas citadas seriam: art. $1^{\circ}$, III (princípio da dignidade da pessoa humana, um dos fundamentos do Estado Democrático de Direito); art. 5º X e XII (direito à privacidade, proteção ao sigilo de dados) respectivamente; art. 225, §1 ${ }^{\circ}$, II (estabelecendo o direito ao meio ambiente equilibrado, acaba por assegurar, também, sua efetividade a partir da preservação da diversidade e da integridade do patrimônio genético do país); dentre outros (ECHTERHOFF, 2010). 
Em matéria de biossegurança nosso ordenamento jurídico conta com uma legislação. Assim, a Lei 8.974/95, hoje revogada pela Lei 11.105/05, ambas atentas para certos aspectos da ciência genética, contudo sem esgotá-la, deixando uma lacuna no ordenamento vigente, inclusive quanto aos aspectos éticos a serem observados com relação ao genoma humano, aos dados genéticos.

A Lei 11.105/20 que em seu artigo $1^{\circ}$ dispõe:

Esta lei estabelece normas de segurança e mecanismos de fiscalização sobre a construção, o cultivo, a produção, a manipulação, o transporte, a transferência, a importação, a exportação, o armazenamento, a pesquisa, a comercialização, o consumo, a liberação no meio ambiente e o descarte de organismos geneticamente modificados - OGM e seus derivados, tendo como diretrizes o estímulo ao avanço científico na área de biossegurança e biotecnologia, a proteção à vida e à saúde humana, animal e vegetal, e a observância do princípio de precaução para a proteção do meio ambiente.

Com bons olhos também se vê que o princípio da precaução é um dos basilares previstos na Lei de Biossegurança conforme seu artigo $1^{\circ}$, tal aspecto será tratado em tópico específico.

No plano infralegal, a regulação jurídica é realizada por Resoluções do Conselho Nacional de Saúde, especificamente pela de número 196/96, complementada pela Resolução 441/2011 que determinam a necessidade de esclarecimento prévio ao sujeito objeto da pesquisa quais são os objetivos da mesma, sua natureza, os métodos, os benefícios, os potenciais riscos e o incômodo que esta possa acarretar ${ }^{15}$ e, mesmo após tais esclarecimentos ainda prevê a necessidade do consentimento para que se possa realizar a pesquisa pretendida.

No que concerne ao direito de decidir sobre o armazenamento, acesso e o fluxo dos dados pessoais este deve ser reconhecido com base na proteção dos direitos de personalidade, da intimidade e da privacidade, consagrados tanto no art. 5 $\mathrm{X}$ do texto constitucional como no art. 21 do Código Civil, repisa-se.

Ocorre que não há qualquer regulação nem mesmo relativa aos bancos de dados, conforme afirmado antes. O que se tem hoje no Brasil, são dois projetos de lei esperando pela aprovação do Congresso Nacional. O PL 3858/ 12, que dispõe sobre a utilização de sistemas biométricos, a proteção de dados

\footnotetext{
${ }^{15}$ http://conselho.saude.gov.br/web_comissoes/conep/aquivos/resolucoes/23_out_versao_final_196 _ENCEP2012.pdf e http://conselho.saude.gov.br/resolucoes/2011/Reso441.pdfAcesso em: 22/04/ 2013).
} 
pessoais e dá outras providências e tipificando também, os crimes de modificação de dados em sistema de informações e o PL 4060/2012 dispondo sobre o tratamento de dados pessoais, e dá outras providências sendo este último mais voltado para as relações de consumo.

Ademais, a regulamentação mais próxima que existe, nos dias de hoje, são as Resoluções n 466/12 do Conselho Nacional de Saúde que apresenta diretrizes e normas regulamentadoras acerca de pesquisas envolvendo seres humanos $n^{\circ} 340 / 04$, que apresenta as diretrizes de análise ética para e tramitação dos projetos de pesquisa na área temática especial de genética humana. Entretanto, elas não normatizam todas as questões de proteção de dados pessoais genéticos e nem tampouco dos bancos de dados. Ressalta, também, que estas Resoluções se tratam de atos normativos e não de leis.

A Resolução 466/2012 no seu item “II - TERMOS E DEFINIÇÕES”, subitem "14" define a pesquisa envolvendo seres humanos como "pesquisa que, individual ou coletivamente, tenha como participante o ser humano, em sua totalidade ou partes dele, e o envolva de forma direta ou indireta. Vê-se que o “manejo de dados” e "informações” compreende o conceito de pesquisa, porém, não especifica qual a proteção que devem receber.

Por outro lado, traz no seu bojo o princípio da finalidade e o consentimento informado se, eventualmente, os dados tiverem de ser utilizados para outros fins, conforme se detecta da leitura do subitem “IV.7” da Resolução comentada:

IV.7 - Na pesquisa que dependa de restrição de informações aos seus participantes, tal fato deverá ser devidamente explicitado e justificado pelo pesquisador responsável ao Sistema CEP/CONEP. Os dados obtidos a partir dos participantes da pesquisa não poderão ser usados para outros fins além dos previstos no protocolo e/ou no consentimento livre e esclarecido.

Percebe-se no Brasil, que mesmo não havendo lei específica em proteção de dados pessoais, no que se refere aos dados genéticos existe uma regulação infralegal, uma autorregulação, que, no entanto, pelo seu conteúdo não trabalha com conceitos específicos, nem prioriza princípios expressos como prevenção e precaução.

\section{A APLICAÇÃO DOS PRINCÍPIOS DA PRECAUÇÃO E DA PREVENÇÃO APLICADOS AO MEIO AMBIENTE VIRTUAL}

O conceito de meio ambiente vem bem definido por Paulo de Bessa Antunes, o autor deixa claro, após um estudo pormenorizado, que compreende 
diversos aspectos: “(i) direito ao meio ambiente, (ii) direito sobre o meio ambiente e (iii) direito do meio ambiente” (ANTUNES, 2012, p. 7)

Importante ressaltar que Paulo de Bessa Antunes não aborda o meio ambiente virtual, e não se depreende de sua obra qualquer consideração a respeito, até porque não é o foco do trabalho do autor. No entanto, expressa que por suas características, o direito ambiental tem que ser "examinado de forma flexível e maleável”. É justamente desde esta perspectiva que se entende cabível analisar a inserção de princípios do meio ambiente físico ao virtual.

Não é sem fundamento a concepção de que meio ambiente está para além da dimensão de natureza. ${ }^{16}$ Pode-se citar como exemplos meio ambiente do trabalho, o meio ambiente da educação à distância que se processa no meio ambiente virtual, no Direito Penal (presunção de inocência) ${ }^{17}$ dentre outras dimensões. Saliente-se que há no Brasil uma experiência bastante profícua no meio ambiente virtual na área de educação à distância. Vários são os cursos promovidos através do uso de tecnologias, sobretudo na área da educação para o tema. ${ }^{18}$

Antes de adentrar-se na análise dos princípios em questão, se faz necessário tecer alguns comentários acerca do Biorrepositórios ou Biobancos já que estes são os locais de armazenamento dos materiais e das informações da pesquisa genética. Há, no Brasil e no mundo, uma preocupação institucional com armazenamento e a transferência de dados relativos à pesquisa genética sobretudo pela inexistência de uma lei ordinária que regule a proteção de dados pessoais e todos os temas a ela relacionados. Esta realidade se torna evidente em artigo acerca das Diretrizes adotadas pelo Brasil em face da ausência de uma lei ordinária que regule a questão. Neste sentido, Gabriela Marondin et al. (2013) se manifestaram textualmente:

Uma preocupação mundial tem sido a constituição de uma rede de biobancos harmonizada, que respeite os preceitos éticos, legais e técnicos dos países integrantes. Nas discussões internacionais, observou-se a necessidade e a importância da viabilidade de cooperação entre instituições locais e de diversos países, bem como a necessidade de harmonização das recomendações com relação aos padrões de linguagem, formas de

\footnotetext{
${ }^{16}$ Neste sentido vide ANTUNES, 2012, p. 7.

${ }^{17}$ Quanto a este ramo do direito vide ANTUNES, 2012, p. 33.

${ }^{18}$ Como exemplo se pode verificar no site do Ministério do Meio Ambiente. Disponível em: http:// www.brasil.gov.br/meio-ambiente/2014/06/mma-lanca-oito-cursos-a-distancia-para-formar-10-milpessoas-1. Acesso: 19/03/2015.
} 
comunicação, sistema de bioinformática e terminologia única para designação dos materiais biológicos humanos.

No mesmo texto, os autores já colocaram de manifestaram que essa ausência de Lei que regule os Biobancos ou Biorrepositórios “fragiliza o controle do Conselho Nacional de Saúde e do próprio Poder Executivo Federal nas atividades de pesquisa envolvendo seres humanos quando efetivadas mediante a remoção de material biológico humano.” (MARODIN et al., 2013) No entanto, enfatizam que os documentos existentes são importantes para regulamentar a matéria. ${ }^{19}$

O mundo digital está permeado pelo incerto. Com todos os avanços das tecnologias da informação e da comunicação (TIC) é impossível prever-se o dia de amanhã. Esta realidade impõe para o Direito, enfrentar-se com uma lógica diferente daquela que por muitos e muitos séculos funcionou. O espaço físico é delimitado e delimitável, ao contrário, o meio ambiente virtual compreende um todo, como se disse antes, as "nuvens".

A lógica no meio ambiente virtual migra do indivíduo para o coletivo. Não se está só. Ademais, como o ciberespaço ${ }^{20}$ funciona com uma dinâmica diferente que lhe é característica, a cada dia se alarga em autonomia desenvolvendo e diferenciações que se afastam do meio ambiente físico (mundo real). No meio ambiente virtual com a velocidade e toda a estrutura de conectividade o ser humano se enfrenta com uma discussão integrada em um universo de parâmetros nunca dantes imaginados e é neste momento que pode perder a noção exata de valores, e conteúdo.

Uma espécie de dialética se estabeleceu em dois universos paralelos baseados em fuga, compensação complementar, a gestão, a exploração e a exposição. Tem-se que admitir que o mundo cibernético não tenha a mesma riqueza, densidade e diversidade do mundo físico (real). Porém, a força da vida que reúne em sua essência e a cada dia é mais fascinante, e está tomando a forma de uma alegoria, de um laboratório do futuro. Agora se está participando destes mundos em uma espécie de hibridez, as vezes "esquizofrênico”, é uma condição que faz com que o universo contemporâneo meio real e meio virtual, seja uma exclusiva mescla social (FISCHER, 2006).

\footnotetext{
19 "Resolução do CNS 441 de 2011, ${ }^{9}$ a qual revoga a Resolução do CNS 347 de 2005, e a Portaria do Ministério da Saúde aqui apresentada, são de grande importância para a regulamentação desta temática, sobretudo quando se considera a constituição e o funcionamento dos novos biobancos brasileiros com fins de pesquisa.” MARODIN et al., 2013.

${ }^{20}$ Aqui entendido como o meio ambiente virtual.
} 
Carlos Alberto Molinaro, sem tratar diretamente dos princípios da precaução e da prevenção, alerta para os riscos advindos da investigação científica, afirmando que a técnica adota mecanismos do que chama de “contramedidas” para diminuir tais riscos. Textualmente afirma:

A ciência - enquanto um conjunto de proposições que expressam leis, objeto de valorações verossímeis sobre os eventos e objetos investigados - produz riscos, mas colabora, também, para eliminá-los ou, pelo menos, reduzir os seus efeitos. Para tanto, desenvolve meios, técnicas que induzem contramedidas aos riscos, no entanto, estas podem produzir outros agravos. Como se pode observar há uma circularidade de "matriz resistiva” cuja função de afirmação da verossimilidade da produção de uma consequência conduz à inferência necessária da veracidade de outra. Como resolver a questão? O direito pode cooperar para a solução. Risco implica responsabilidade, responsabilidade enquanto obrigação de responder pelo dano produzido tenha este como origem causa natural ou antrópica. Especialmente nos casos dos danos ambientais, responsabilidade política que reclama a decidida intervenção dos poderes públicos, não com uma orientação reparadora, mas de prevenção, de precaução, redução e, no possível, eliminação dos riscos39, neste viés a importância da qualidade da regulação. ${ }^{21}$

Fundamentalmente, tem-se que lembrar que a internet é um fenômeno global que enseja as mais diversas possibilidades de controle, monitoramento e transferência de dados e informações. Neste sentido, Ivan Hartmann (2007, p. 10) estudando o tema de acesso à internet como um direito fundamental afirma que:

O espectro espacial da monitoração de dados dos indivíduos passa a ser significativamente estendido pelas possibilidades da computação ubíqua, ao passo que a cobertura temporal dessa monitoração cresce juntamente com a capacidade de armazenamento: uma autoridade governamental poderá, mediante simples acesso ao banco de dados referente a um determinado indivíduo, ser informada de diagnósticos pré-natais deste último.

Para poder compatibilizar tais mundos (físico e digital) e vivenciar adequadamente a realidade que está posta no meio ambiente virtual, dentre

\footnotetext{
${ }^{21}$ Disponível em> https://www.google.com.br/webhp?sourceid=chrome-instant\&ion=1\&espv= $2 \& i e=U T F-8 \# q=A+c i \% C 3 \% A A n c i a+\% E 2 \% 80 \% 93+$ enquanto $+u m+$ conjunto + de + proposi \%C3\%A7\%. Acesso em: 19/03/2015. p. 12.
} 
muitos fatores já apontados em artigo anteriormente publicado, ${ }^{22}$ necessita-se de mecanismos que provenham um funcionamento adequado, por exemplo, a lei e os princípios.

No que concerne ao princípio da precaução, o mesmo está previsto no artigo $1^{\circ}$ da Lei de Biossegurança - 11.105/05, onde está expressa sua conexão com o meio ambiente. Vê-se que o princípio da precaução compõe o sistema jurídico no meio ambiente físico.

O princípio da precaução tem demandado muitas discussões jurídicas a ponto de não se ter um consenso quanto ao conteúdo essencial, cabendo então, marcar sua definição para efeitos de seu alcance no meio ambiente virtual.

A importância do princípio da precaução se constitui na vinculação da ação humana não só com o presente, mas também com o futuro, atua prospectivamente. Por tal motivo é considerado como "um dos pilares mais importantes da tutela jurídica do ambiente” (SARLET; FESNTERSEIFER, 2014, p. 164). Ademais, incorpora uma ética de responsabilidade na convivência das pessoas no meio ambiente em geral e, inclusive o virtual.

A ética em pesquisa e particularmente em pesquisa genética já tem incorporada a responsabilidade nesta seara nas diversas Convenções e Pactos Internacionais, bem como nas Resoluções no Brasil. No entanto, tal realidade não se faz presente em normas legais específicas de proteção de dados genéticos, no seu tratamento, armazenamento e transferência e não se faz porque não há uma lei específica de proteção de dados pessoais em nosso ordenamento conforme já se disse anteriormente, ao longo deste artigo.

Note-se que de acordo com o artigo $4^{\circ}$ da Declaração Internacional de Dados Genéticos Humanos preconiza a especificidade dos dados genéticos em face de que:

(a) A especificidade dos dados genéticos humanos decorre do facto de:

(i) Serem preditivas de predisposições genéticas dos indivíduos;

(ii) poderem ter um impacto significativo sobre a família, incluindo a descendência, ao longo de várias gerações, e em certos casos sobre todo o grupo a que pertence a pessoa em causa;

(iii) poderem conter informações cuja importância não é necessariamente conhecida no momento em que são recolhidas as amostras biológicas;

(iv) poderem revestir-se de importância cultural para pessoas ou grupos.

(b) É necessário prestar a devida atenção ao carácter sensível dos dados

${ }^{22}$ MOLINARO; RUARO, 2013. 
genéticos humanos e garantir um nível de protecção adequado a esses dados e às amostras biológicas. ${ }^{23}$

A Declaração comentada ao abordar a singularidade dos dados genéticos deixa evidente a necessidade de proteção que os mesmos devem ter em face de serem dados sensíveis. Com isto, pode-se inferir que ao realizar pesquisa genética, os investigadores terão que agir de forma prudente.

O princípio da precaução decorre justamente das especificidades apontadas pela Declaração. Note-se que o artigo 4, item “(ii)” expressa a possibilidade de "um impacto significativo sobre a família, incluindo a descendência ...” a ética está para além da relação entre o pesquisador e o pesquisado porque residem nas pesquisas desta natureza um grau de incerteza quanto a seus resultados.

Pelo princípio da precaução, não se tem como seguro que haverá impacto, mas se pode vislumbrar a existência de um problema desta ordem o que caracteriza um dos pressupostos para a aplicação do princípio da precaução. É claro que as medidas de precaução devem ser tomadas na presença de temores razoáveis sob pena de se provocar limitações desastrosas nas investigações científicas.

Juarez Freitas (2013, p. 125) estudando o princípio da precaução faz a ressalva de que é "inadmissível a tomada de medidas de precaução em virtude de temores desarrazoados”.

Transportando tal princípio para o campo da pesquisa genética tem-se que sua aplicação é deveras importante. Assim se manifesta José Roberto Goldin (2002, p. 1) ao sustentar:

Este princípio tem uma clara e decisiva utilização na Bioética. Tomando apenas a questão da saúde, ela sempre esteve associada à noção de dano. Quando era entendida apenas como a ausência de doença, a saúde era tida como o estado onde o indivíduo estava livre de danos que estariam ocorrendo naquele momento. A própria atividade dos profissionais de saúde também era associada à noção de dano. Hipócrates, cerca de 400 anos aC, propôs que ao tratar os doentes o primeiro dever era o de ajudar e o segundo o de não causar dano.

${ }^{23}$ Disponível em: http://bvsms.saude.gov.br/bvs/publicacoes/declaracao_inter_dados_genericos.pdf. Acesso em: 16/03/2015. 
Estudando o Direito Ambiental, Cançado Trindade (1993, p. 75) entende que cabe ao Estado empregar "sistemas de monitoramento e alerta imediato" para detectar riscos ambientais sérios e "sistemas de ação urgente" com tais situações. Não sem outra razão para além do meio ambiente físico, também no meio ambiente virtual apresenta-se a necessidade de que o Estado, através de normativas específicas em proteção de dados, que abarque os dados genéticos como dados sensíveis, lance mão de uma lei capaz de incorporar o princípio da precaução.

Há de se ter em conta que o Projeto Genoma Humano, evidencia questionamentos ético-jurídicos que limitem a incidência de afronto à dignidade humana, posto que trabalhar em pesquisa genética sem as precauções necessárias no tratamento de dados, bem como sua transferência ou má utilização levam a resultados como, por exemplo, a colisão de direitos fundamentais. ${ }^{24}$

Relativamente ao princípio da prevenção, este se diferencia do principio da precaução "reside no grau estimado de probabilidade de ocorrência do dano (certeza versus verossimilhança)” (FREITAS, 2013, p. 125).

Enquanto no princípio da precaução não se tem conhecimento completo sobre os efeitos que podem resultar de determinada técnica de pesquisa, de sua utilização, armazenamento e transferência de dados, no princípio da prevenção já se antevê o resultado. No princípio da prevenção tem-se a "verdade sabida” e o potencial lesivo já é conhecido. Não se vai longe. Diuturnamente vazam na internet dados pessoais, fotos e outras informações de tratamento potencial lesivo a ponto de provocarem graves consequências para os afetados. ${ }^{25}$

O princípio da prevenção, ainda que não esteja expresso em nomenclatura, está previsto implicitamente como princípio 5, na Declaração de Estocolmo sobre o Meio Ambiente Humano de $1972{ }^{26}$ “Os recursos não renováveis da terra devem empregar-se de forma que se evite o perigo de seu futuro esgotamento e se assegure que toda a humanidade compartilhe dos benefícios de sua utilização”.

\footnotetext{
${ }^{24}$ Neste aspecto pode-se citar a discriminação de pessoas em razão de propensão genética a determinada enfermidade por Planos de Saúde.

${ }^{25}$ Um exemplo é o caso ocorrido em 2013 onde uma adolescente de 16 cometeu suicídio em Veranópolis/ RS em razão de fotos intimas suas terem sido publicadas na internet. Disponível em: http:// noticias.terra.com.br/brasil/policia/rs-adolescente-comete-suicidio-apos-ter-fotos-intimasdivulgadas-na-web,1b975df8bd472410VgnVCM5000009ccceb0aRCRD.html. Acesso

${ }^{26}$ Disponível em: http://www.direitoshumanos.usp.br/index.php/Meio-Ambiente/declaracao-deestocolmo-sobre-o-ambiente-humano.html
} 
No ordenamento jurídico, várias são as disposições legais que tratam do princípio da prevenção ${ }^{27}$ todas elas voltadas para a preservação do meio ambiente físico.

Com efeito, as degradações do meio ambiente atingem a sustentabilidade existencial, já as degradações ocorridas no meio ambiente virtual atingem os seres humanos em sua essência psíquica, emocional e por isto são tão graves quanto aquelas. Diante tal realidade, a pesquisa genética em matéria de armazenamento, tratamento e transferência de dados pessoais deve, sobretudo, no mundo digital incorporar os princípios da precaução e da prevenção.

Como bem aponta Paulo Affonso Leme Machado (2006, p. 72):

Em caso de certeza de dano ambiental, este deve ser prevenido, como preconiza o princípio da prevenção. Em caso de dúvida ou de incerteza, também se deve agir prevenindo. [...] A dúvida científica, expressa com argumentos razoáveis, não dispensa a prevenção.

O princípio da prevenção não contém em seu significado a eliminação o dano, mas, em se tendo consciência de que ato poderá gerar problema poderá, é a partir do estabelecimento de nexo causal que seja pertinente com impactos que daí possa advir (ANTUNES, 2012), que cabe ao Direito aportar normas que sejam capazes de evitar o mal maior.

\section{CONSIDERAÇÕES FINAIS}

Analisar os problemas relacionados à era digital passa por levar em conta seus conflitos e paradoxos. Essa realidade se manifesta e, por vezes se agrava quando diante de conflitos entre direitos fundamentais. O mundo digital está em um meio ambiente virtual que expande fronteiras. Por tal razão, tem, necessariamente, que comunicar-se com conceitos meta-jurídicos. Inicialmente parte do escopo de privacidade, embora termine por superá-la, dotando-lhe de novo significado e funcionando como espaço de mediação da nova realidade.

A transição do meio ambiente físico para o meio ambiente virtual, no entanto, longe de acabar - porque é uma realidade irreversível - , apenas descreve seus contornos da superfície, tornando clara a necessidade de aplicar-se princípios capazes de minimizar ou evitar riscos.

\footnotetext{
${ }^{27}$ A respeito do tema vide: SARLET; FENSTERSEIFER, 2014.
} 
Além das dificuldades de se impor limites aos direitos fundamentais sem atingir seu conteúdo essencial e, em face de uma organização normativa ainda incipiente no Brasil marcada pela ausência de Lei de proteção de dados, depara-se com as dificuldades que a tecnologia agrega neste campo.

O estabelecimento de um sistema legal de proteção de dados pessoais onde se inclua os dados pessoais genéticos visando uma regulamentação adequada, implica em consequências, inevitavelmente, pode provocar choque de interesses e por isto, deve, necessariamente, resultar em esforço legislativo que leve a um avanço tecnológico adequado para explicar todas as contingências no debate em questão.

No presente artigo, sem a pretensão de esgotar a matéria porquanto muito se tem a estudar e discutir, inclusive analisando normativas do direito comparado - o que não foi objeto do trabalho - procurou-se responder, ainda que em parte, a alguns questionamentos.

Assim pode-se concluir que:

(a) uma das formas para compatibilizar direitos consagrados na Constituição Federal de 1988 diretamente relacionados com a dignidade da pessoa humana - como o respeito à vida privada e à intimidade - frente à liberdade de pesquisa genética é a utilização é a imposição de limites sem que com isto de anule o conteúdo essencial de qualquer dos direitos em questão;

(b) o significado que uma tutela aos dados pessoais no campo da informação genética recebe do ordenamento jurídico brasileiro importante, porém, em face da inexistência de uma lei de proteção de dados pessoais onde se incluam medidas protetivas dos dados pessoais genéticos, torna tal direito fragilizado e diminui o âmbito de controle de organismos estatais.

(c) a existência do meio ambiente digital onde transitam dados pessoais genéticos agrava qualquer consequência advinda de seu vazamento ou má utilização o que faz com que, a aplicação dos princípios da prevenção e da precaução no meio ambiente virtual seja imprescindível para a consecução dos direitos fundamentais objeto do estudo.

Além disso, a concepção de uma ideia de dignidade da pessoa humana e privacidade de dados genéticos quando diante da liberdade de pesquisa apresenta-se como semelhante às placas tectônicas em arrastar, cujo epicentro é identificado no uso da internet por todos. Esse é o "calcanhar de Aquiles” dos operadores do Direito e dos pesquisadores na matéria. 


\section{REFERÊNCIAS}

ALARCÓN, Pietro de Jesús Lora. Patrimônio genético humano e sua proteção na constituição federal de 1988. São Paulo: Método. 2004.

ANTUNES, Paulo Bessa. Direito ambiental. 4ªd. São Paulo: Editora Atlas. 2012.

CANÇADO TRINDADE, Antonio Augusto. Direitos humanos e meio ambiente: paralelo dos sistemas de proteção internacional. Porto Alegre: SAFE, 1993.

CANOTILHO, J.J. Gomes. Direito constitucional e teoria da constituição. 7 ed. Coimbra: Almedina, 2000.

CASABOnA, Carlos Maria Romeo. Biotecnologia, Direito e Bioética. PUC Minas, Del Rey: Belo Horizonte, 2002.

CLOTET, Joaquim. Bioética uma aproximação. Porto Alegre: Edipucrs, 2003.

CÔRREA, Adriana Espindola. Tese: O corpo digitalizado: banco de dados genéticos e sua regulação jurídica. Curitiba, 2009.

COSTA JÚNIOR, Paulo José da. O direito de estar só: tutela penal da intimidade. São Paulo: Revista dos Tribunais, 1970.

DONEDA, Danilo. A tutela da privacidade no código civil de 2002. p. 1. Disponível em: <http://www.anima-opet.com.br/primeira_edicao/ artigo_Danilo_Doneda_a_tutela.pdf $>$. Acesso em 09/10/2014.

ECHTTERHOFF, Gisele. Direito à privacidade dos dados genéticos. Curitiba: Juruá Editora. 2010.

FISCHER, Hervé. Digital Shock - Confronting the New Reality. Quebec, Canada: McGill-Queen’s University Press, 2006.

FREITAS, Juarez. O controle dos atos administrativos e os princípios fundamentais. São Paulo: Malheiros Editores. 5ª ed. 2013. 
GOLDIN, José Roberto. O princípio da precaução. Disponível em: http:// www.ufrgs.br/bioetica/precau.htm. Acesso em: 18/03/2015.

HARTMANN, Ivan. O acesso à internet como direito fundamental. Disponível em: http://www3.pucrs.br/pucrs/files/uni/poa/direito/graduacao/ tcc/tcc2/trabalhos2007_1/ivar_hartmann.pdf. Acesso em: 19/03/2015.

MACHADO, Paulo Affonso Leme. Direito ambiental brasileiro. 14 ed. São Paulo: Malheiros Editores Ltda. 2006.

MARODIN, Gabriela. SALGUEIRO, Jennifer Braathen. MOTTA, Márcia da Luz. SANTOS, Leonor Maria Pacheco. Diretrizes nacionais para biorrepositório e biobanco de material biológico humano. Disponível em: http://www.scielo.br/scielo.php?script=sci_arttext\&pid=S010442302013000100014. Acesso em: 24/03/2015.

MOLINARO, Carlos Alberto, RUARO, Regina Linden. Internet y estado de vigilancia: El desafio de la protección de datos. Na Revista Social Science Reserch Network. p.1/12. Agosto-2013. Disponível em: http://dx.doi.org/ 10.2139/ssrn.2310267. Acesso em: 20/03/2015.

MORAES, Alexandre de. Constituição do Brasil interpretada e legislação constitucional 5a edição. São Paulo: Atlas, 2005.

OTTO Y PARDO, Ignacio de. La regulación del ejercício de los derechos y libertades. Madrid: Cuadernos Civitas. 1988.

PETERLE, Selma Rodrigues. $\mathbf{O}$ direito fundamental à intimidade genética na constituição brasileira. Porto Alegre: Livraria do Advogado Editora. 2007.

RODOTÀ, Stefano. A vida na sociedade de vigilância: a privacidade hoje. Rio de Janeiro: Renovar, 2008.

RUARO, Regina Linden, RODRIGUEZ, Daniel Piñeiro e FINGER, Brunize (Colaboradora). $\mathbf{O}$ direito à proteção de dados pessoais e a privacidade. p. 187-188. Disponível em: 
$<$ http://www.egov.ufsc.br/portal/sites/default/files/

o_direito_a_protecao_de_dados_pessoais_e_a_privacidade_0.pdf $>$. Acesso em: 22 out. 2014.

RUARO, Regina Linden. LIMBERGER, Temis. Banco de dados de informações genéticas e a Administração Pública como concretizadora da proteção dos dados pessoais e da dignidade humana. In: Revista Novos Estudos Jurídicos - UNIVALI. Vol. 18. 2013.

RYDLEWSKI, Carlos. Computação sem fronteiras. Veja. Disponível em: http://veja.abril.com.br/120809/computacao-sem-fronteiras-p-062.shtml. Acesso em: 10/03/2015.

SANTOS, Maria Celeste Cordeiro Leite. Biodireito: ciência da vida, os novos desafios. São Paulo: Editora Revista dos Tribunais, 2001.

SARLET, Ingo Wolfgang. A eficácia dos direitos fundamentais. $12^{\mathrm{a}}$ ed. Porto Alegre: Livraria do Advogado. 2015a.

SARLET, Ingo Wolfgang. FESNTERSEIFER, Tiago. Princípios do direito ambiental. São Paulo: Editora Saraiva. 2014.

SARLET, Ingo Wolfgang. MARINONI, Luiz Guilherme, MITIDIERO, Daniel. Curso de Direito Constitucional: o âmbito de proteção dos direitos e garantias fundamentais. $3^{\mathrm{a}}$ edição. São Paulo: Editora Revista dos Tribunais, 2014.

SARLET, Ingo Wolfgang. O princípio da dignidade da pessoa humana e os direitos fundamentais. 2. ed. Porto Alegre: Livraria do Advogado, 2015b.

SILVA, Virgílio Afonso da. Direitos fundamentais. Conteúdo essencial, restrições e eficácia. $2^{\mathrm{a}}$ ed., $3^{\mathrm{a}}$ tiragem. São Paulo: Malheiros Editores. 2014.

VIEIRA, Tatiana Malta. $\mathbf{O}$ direito à privacidade na sociedade da informação, efetividade desse direito fundamental diante dos avanços 
da tecnologia da informação. Porto Alegre: Sergio Antonio Fabris Editor, 2007.

WARREN e BRANDEIS, “The right to privacy”. Harvard law review.

Disponível em: <http://groups.csail.mit.edu/mac/classes/6.805/articles/

privacy/Privacy_brand_warr2.html>. Acesso em: 13/03/2015.

Artigo recebido em: 15/06/2015

Aprovado para publicação em: 10/08/2015

Como citar: RUARO, Regina Linden. Direito fundamental à liberdade de pesquisa genética e à proteção de dados pessoais: os princípios da prevenção e da precaução como garantia do direito à vida privada. Revista do Direito Público. Londrina, v.11, n.2, p.9-38, mai./ago. 2015. DOI: 10.5433/ 1980-511X.2015v10n2p9. 